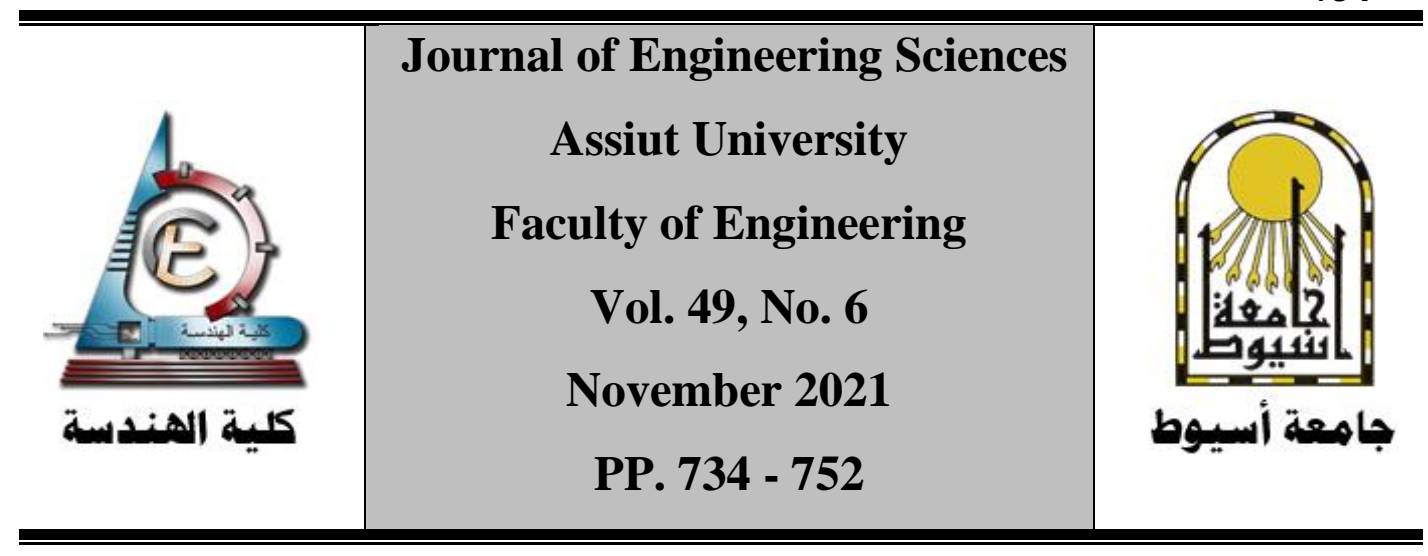

\title{
Simulating Cash Flow Model for Mega Construction Projects in Egypt
}

\author{
Yasser M. R. Aboelmagd
}

${ }^{1}$ Associate Professor Department of Civil Engineering, College of Engineering, University of Business \& Technology (UBT), Jeddah, Saudi Arabia yasser@ubt.edu.sa

${ }^{2}$ Assistant Professor Department of Mathematics and Physics Engineering, Faculty of Engineering, Alexandria University, Egypt.

yasser.aboelmajd@alexu.edu.eg

Received 9 June 2021; Revised 31 July 2021; Accepted 23 August 2021

\begin{abstract}
This research presents a cash flow construction road projects prediction model. The model based upon actual current invoices analysis and payments data of road construction projects. Initial results indicate that this simple model is best way for predicting future cash flows especially construction road projects. The main concern is to look at highway road tender projects. This investigation could be used by road authorities who manage multiple projects. It could be used for providing a forecast technique of new project payments. Latest research from General Authority for Road, Bridges and Land Transporting (GARBLT) projects from 2003 to 2020 were analyzed. This data is used to implement mathematical models for road construction to represent monthly payment invoices for different project types. Cost estimates of financial data were collected from 78 highway road contracts which are consist of 46 highway strengthening contracts and 32 highway overlay contracts. All collected data from field was arranged into main
\end{abstract}


categories and/or subcategories according to project type and contract amount. A polynomial regression analysis for seventh degree is done for all collected data, and then regression curve is constructed. Statistically equations were performed and taken into research consideration can provide payment curve expectation. Finally, proposed built in model by using Microsoft Excel was implemented to develop investigation results. The proposed model was named as Multi Road Projects Cash Flow Model "MRPCFM". Provided research methodology can help highway sectors to enforce their projects to proposed model for expect better cash flow predictions. This investigation may give more benefits to related researchers for predicting cash flows and directions. Also, any agency could provide improvements for the model. The tender information concept was used to analyze and draw cash flow estimations in contracted projects execution stage, to understand the goal of short-term financial demands which are occurring during execution stage. In practice, owners of the road projects can use the model to show amount demanded and cash distribution before the projects execution to revise and update new predictions from previous actual cash flow data.

Keywords: Construction management; Road Construction; Prediction Model; Spread Sheets, Cash Flow; Profitability, Progress, and Egypt.

\section{INTRODUCTION}

Management for road construction cash flow is the most essential determinants for construction project management success. Therefore, expected cash demands expectation during tender phase is very important issue to contractors. Due to related study, cash flow problems through implementation initial period might more control performance for engineering project and it difficult for controlling causes which may lead to crisis in financial of construction industry. It is noted that cash flow for construction project is very essential sources in financial analysis. Therefore, if cash flow prediction and or analysis can be completed before beginning of construction project that means it helps to know cash demands in advance during construction phase. It focuses on cash flow amount and its timing, which was critical to efficient budget management through construction phase. It is important to identify individual outflow or inflow time and amount at each period end, contractors can also expect cash flow at a certain time due to 
project progress. Diagrams of cash flow are representing the timing by a horizontal line investigated with interest period's number using arrows to show cash flows over time at pertinent periods. But that will be different when we look from public owner points of view as an owner not a contractor. It is needed to compare the present value of initial construction and future maintenance costs across different road structure and technologies so it can be achieving an accurate assessment with clear information about the cash flow and its timing. Construction projects related to highway require drivers' real costs that they are delayed for local businesses and may interrupted on environment. The General Authority for Roads, Bridges and Land Transport "GARBLT" try to construct best and fastest highway projects using the latest information's and research in that field. This way will increase the road users and traffic volumes with low costs and higher delays. To get fastest highway construction projects should use projects available funds and to optimize road life cycle cost GARBLT must select appropriate "practice state" methods to accelerate construction process. Concurrently, quality and value of roads should be maintained in professional way. Therefore, scheduling problems must be solved by researchers using integration between financial factors with scheduling to assist contractors by excellent performance for maximizing project profit and minimizing project duration as contractor's view. As a result, it can be getting clear cash flow information through the estimated time of the construction projects before the beginning of these projects which is the scope of this paper.

\section{BACKGROUND}

The company cash flow controlling is the sensitive part as blood pressure control of human, (Schellenger, Cross 1994). So, it is important to find the correct decision after predicting is considered, (Mehrani et al 2005). That means good decision making by finding the ability to predict phenomena uncontrollable aspects, then decisions improve during increasing awareness for onward situation, (Gholamreza Kordestani, Vahid Biglari, Mehrdad Bakhtiari, 2011). More concerns focus on cash flow amount and its timing, while Profit is an artificial motif, cash flow defined as real objective during construction phase (Ibrahim Lubwama, 2006). More studies presented 
statistical models to predict project cash flow, (Navon, 1996). Best way for forecasting organizational cash flow must develop company management system level with accepting projects advantage for detailing levels varying degrees. Also (Rein Schmidt and Frank, 1977) proposed a new management model based on probabilistic cash flow for helping managers test the reactive effects between cash flow with project schedule alternate, (Kenley ,1999). The country transportation intensity increases because of transit communication country convenient. The roads deteriorate condition pavements become down and technologies had implemented to increase pavement structures strength with building road pavement layers had developed; road pavements structural performance also road pavements should be investigated under real conditions, (Cygas et al, 2008) (8). Infrastructure of roads is essential economic development for any country because transportation was turned into a human life integral part and helps to meet human satisfactions with creating new needs. Unfortunately, any changes create new problems such as time loss, traffic jams, pollution, and noise, (Skrodenis et al, 2009). Road's investments are often appraised from social, environmental, and economical viewpoints, (E. Simon, G. E. Gibson, C. T. Haas, J. T. O'Connor, B. Somali, Z. Zhang, 2002). The cash flow forecasting model provides an estimate of total annual payouts so that anticipated future cash outlays can be measured against available enacted appropriation balances, (Joseph Prather, 2008). To solve the gap of modeling large scale construction road projects, it was developed a hierarchical method for road layout. New method was established by 3 levels for distinguishing traffic demands outside and or inside subprojects, (Tian et. al. 2020). The project's cost contingency finding is a pervasive problem that involved into estimation of road construction projects and difficult to estimate actual cost overrun which experienced in forty-nine new projects procured using lump contracts were analyzed by new modeling, (Peter et. al. 2015). (Dan et. al. 2019) developed a new occupational health management model. (Pramen et. el. 2017), demonstrated change orders values and its effects of on schedule and cost were similar to future road construction projects. (Liang et. el. 2021), created an expenditure cash-flow forecasting model for transportation design-build projects based on case-based reasoning and a genetic algorithm. The proposed model utilized information about project-specific characteristics and external market 
factors. The applicability of the proposed model is examined on a data set of 33 transportation design-build projects delivered by Georgia Department of Transportation (GDOT) from April 2007 to January 2020. The major contribution is lies on the creation of a new forecasting model, which enables reasonably accurate prediction of expenditure cash flow of transportation design-build projects. This study identified that even early at the procurement phase of a designbuild project when exact quantities and detailed cost estimates have not been fully developed, the combination of conceptual project information and local construction market indicators offers the capability to predict the future expenditure cash flow of the project through establishing similarities between the project to be awarded and historical design-build projects. This study provided a novel approach to quantify the similarities that will be used as critical inputs into a case-based reasoning algorithm for predicting the expenditure cash flow of the project using expenditure records of most similar historical projects in the design-build data set. It is anticipated that transportation agencies can benefit from the forecasting model presented in this study by enhancing their processes of estimating their financial obligations on the onset of letting design-build contracts.

\section{ROAD CONSTRUCTION CASH FLOW ANALYSIS}

\section{Typical Project Cash Flow}

Cash flow of road construction Project was computed based on evaluated cost and revenue over construction phase. Values appears schedule as shown as S-curve in costs over project construction life and estimated progress as shown in Fig. 1. There are two cash flow kindsbased expectation models for serving benchmarks to assess the construction projects cash flow incremental predictive ability. The first kind of models depends on a full study of a specific project involving several stages. There is a lot of software which goes through these steps such as PRIMAVERA. The second kind of models which are studying in this research depends on previous results of the matching conditions projects. 


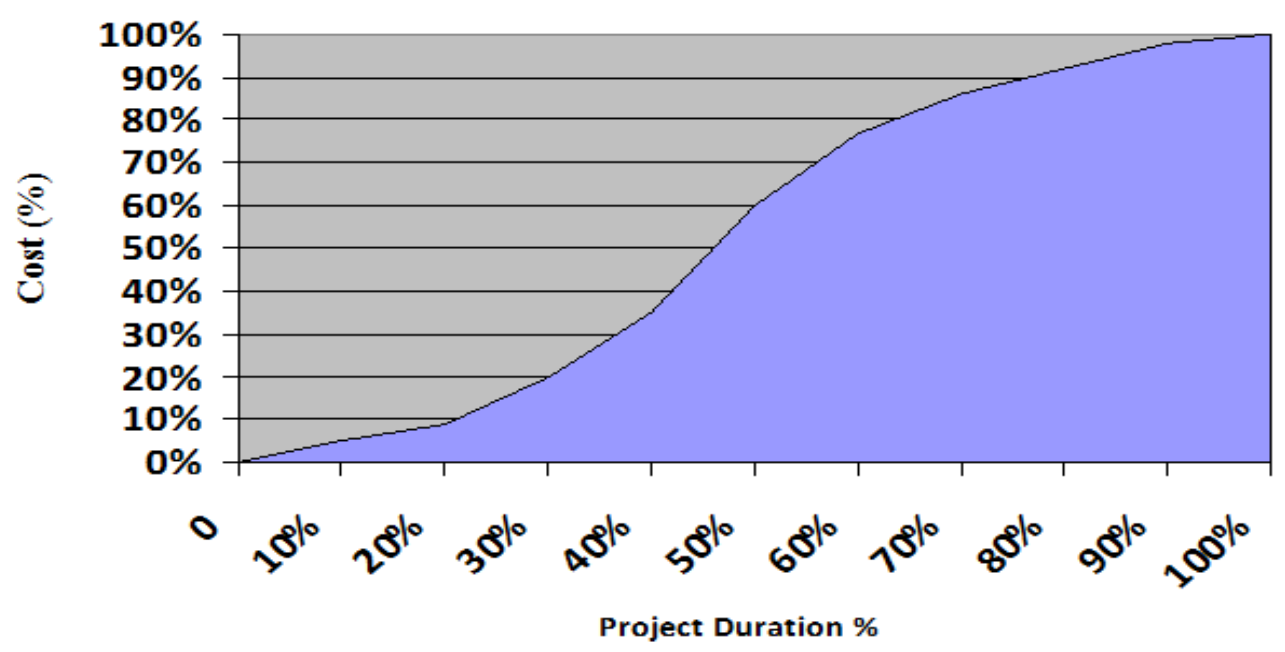

Figure 1. Typical Cash Flow for construction Projects. (Reinschmidt and Frank 1977)

\section{Research Design}

The main concept of this research is preparing a model that can predict cash flow developing through the whole time of projects in field of road construction is the main concern. So, that it could allow determining the amount of cash needed every specific period. Information about cash flow is very important especially to owner which is mostly a governmental authority such as infrastructure projects. These authorities usually are responsible for financing a huge number of projects with various budgets. So, the model is prepared in this paper which is named as multi road projects cash flow model "MRPCFM" could have a great role for helping the road authorities in determining the amount and timing with payment for the all-road construction projects. The results of proposed model shall make a fully prediction for budget required to fund projects on future. The MRPCFM for highway project payment data was developed by monthly account summary reports. Following step is to organize into spreadsheet, data is transcribed with plan can develop new approach for dealing with data. Planning phase divided the data into categories according to project type and other subcategories, set criteria for eliminating abnormal data and or incomplete data, and then payment fraction was analyzed versus of time fraction, that called time charge by using regression of polynomial. After projects were excluded due to had delays or incomplete data from cost overruns, suspensions or 
claims, data were subcategorized after filtered by project contract amount. Final adjustments accomplished regression results were recorded, which their equations were developed into a Microsoft Excel to be easily for use. In first step data was divided into different project types for results and analysis as defined by GARBLT. Next steps eliminate abnormal data and or incomplete data by running filter criteria. After filtration analysis must done on data point's significant number, and finally decided to use requirements minimum number for analysis (only five completed projects). See Fig. 2 for paper methodology.

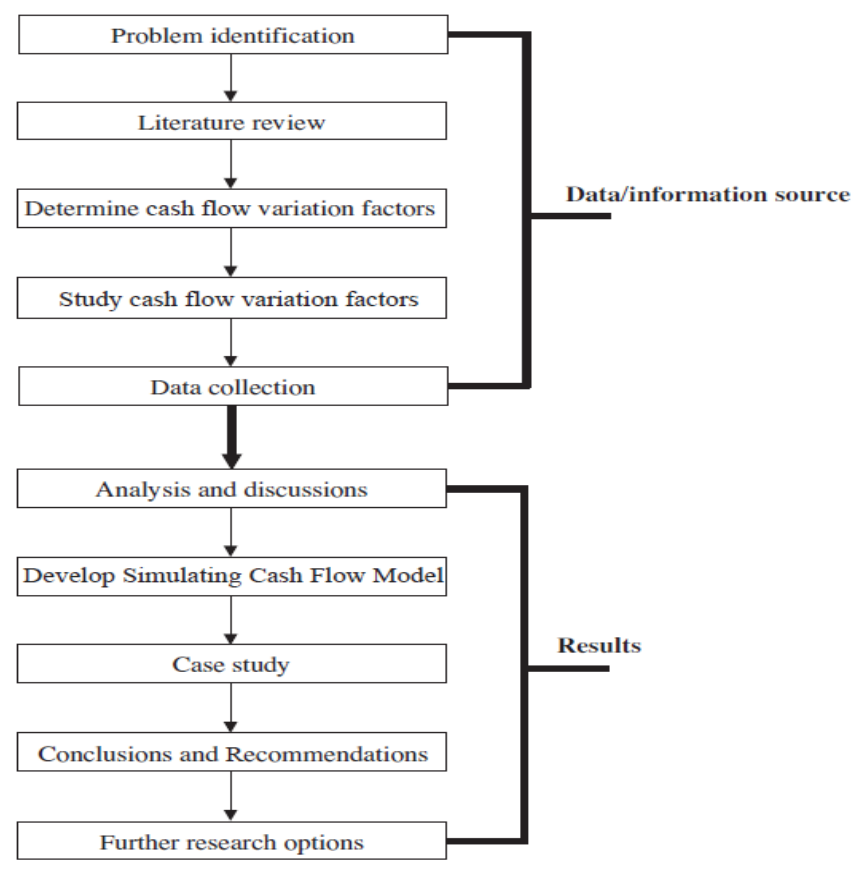

Figure 2 Research main activities/methodology.

\section{Data Preprocessing}

The data was used consisted of 28 projects that were financed through GARBLT (The Authority of Roads, Bridges and Land Transporting). All projects were executed in West and Middle of Delta especially in the next five provinces (Alexandria, Elbhera, Elgharbia, Kafr-elshieh and Matrouh). Monthly account summary reports were collected for every project. Then data are reproduced into spread sheet, it is orderly to can be analyzed and shoe in best exemplification for projects different types. The data in each project are reproduced in new sheet to 
can be analyzed correctly. Each project data is sorted by identification number and saved in database of project details sheet. Finally in last process put projects different type in different files to arrange the data. Information about every project was classified to basic information (project name, start date, imposed finish date, total budget, total duration, and real finish date), payment Time and value and cash flow data.

Plotting previous data is a very important step to review the demanded data in a simple way. $\mathrm{X}$-axis is represented as the time Percentage (days passed divided by actual duration in cases of completed projects and divided by contract duration in cases of uncompleted projects), while $\mathrm{Y}$-axis is represented as cumulative percentage (the total amount paid is divided by actual amount in case of completed projects and is divided by contract amount in case of uncompleted projects) as shown in Fig 3. Through Fig 3, it noticed that:

\section{- All cases are showed as S-curve.}

- Developing the cash percent at the late stages is greater than at the earlier stages which are normally in road projects such as asphaltic activities with high cost and rapid executing rate mostly start at late stages. The data are classified into different road project types as showed in table 1 . Table 1 give all projects' data, the data was filtered by applied the following elimination criteria: (1) any category had less than 5 projects, was removed, (2) a completed project was considered if $60 \%$ or more of its total time was passed and its data was contained, (3) any project missing exceed than $50 \%$ of its data is removed entirely and any project have percent paid more than $120 \%$ is removed entirely, (4) any project had explicit delays is removed entirely. Different contract amounts would lead to curves of different payment according to project size. So, every type was subdivided into three subcategories for analysis (High budget, mid budget, and Low budget) due to complete projects considerable number which are available after filtration. Table 2 shows the data after filtration.

Table 1. Total Projects Number before filtration process.

\begin{tabular}{ccc}
\hline Type & Classification & Total number \\
\hline OV & Overlay projects & 8 \\
ST & Strengthening projects & 17 \\
BR & Bridge's construction & 1 \\
TS & Traffic safety & 1 \\
\hline
\end{tabular}


Table 2. Projects classification after Filtration.

\begin{tabular}{cccccc}
\hline Type & Classification & $\begin{array}{c}\text { Total } \\
\text { number }\end{array}$ & $\begin{array}{c}\text { High } \\
\text { budget }\end{array}$ & $\begin{array}{c}\text { Mid } \\
\text { budget }\end{array}$ & $\begin{array}{c}\text { Low } \\
\text { budget }\end{array}$ \\
\hline OV & Overlay projects & 8 & 2 & 3 & 3 \\
ST & $\begin{array}{c}\text { Strengthening } \\
\text { projects }\end{array}$ & 16 & 5 & 6 & 5 \\
& & & & \\
\hline
\end{tabular}

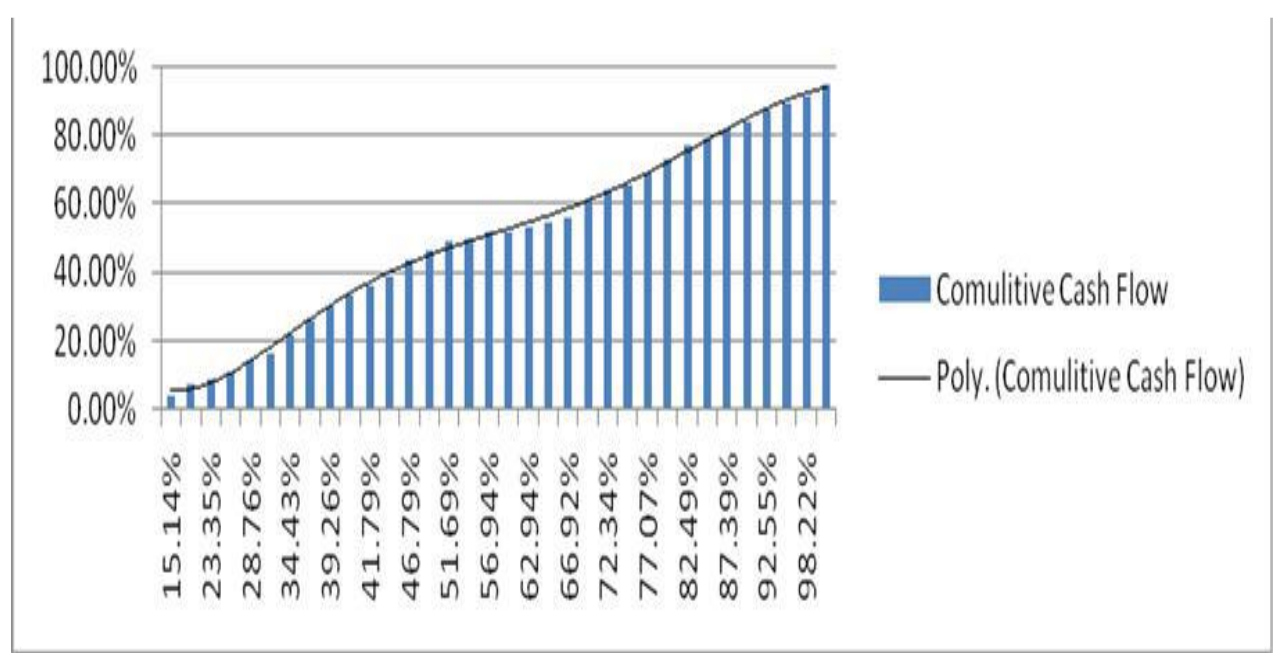

Figure3. Cumulative Cash Flow Diagram for one of the studied projects.

The curves for each category of projects were plotted and was applied the average curve on the chart as shown in the Figure 4.

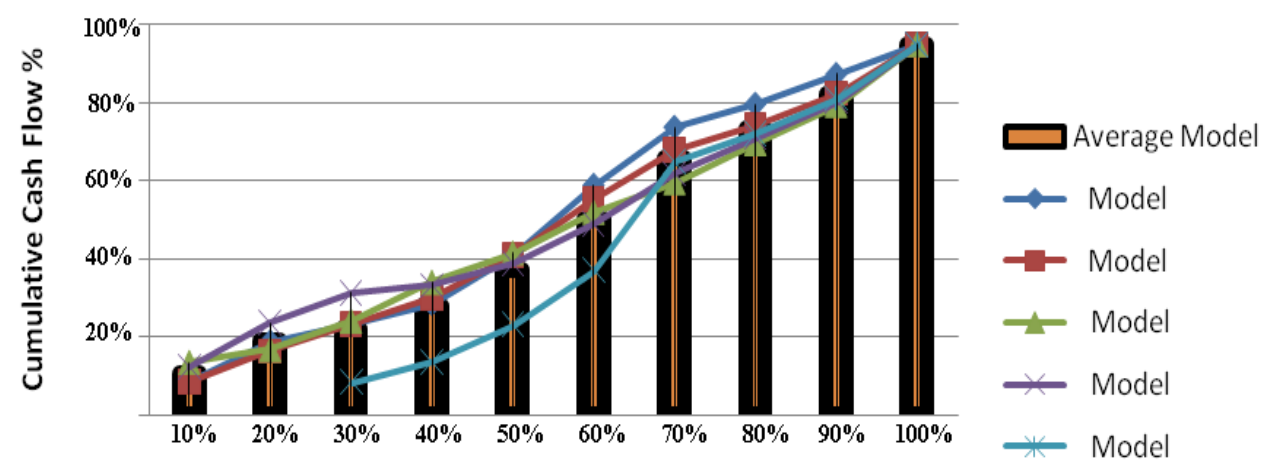

Project Duration \%

Figure4. Curves of Low Budget Strengthening Case. 
Fig.5 shows the average curve of Low Budget strengthening project as a sample and the related equations of each case will appear at the following section.

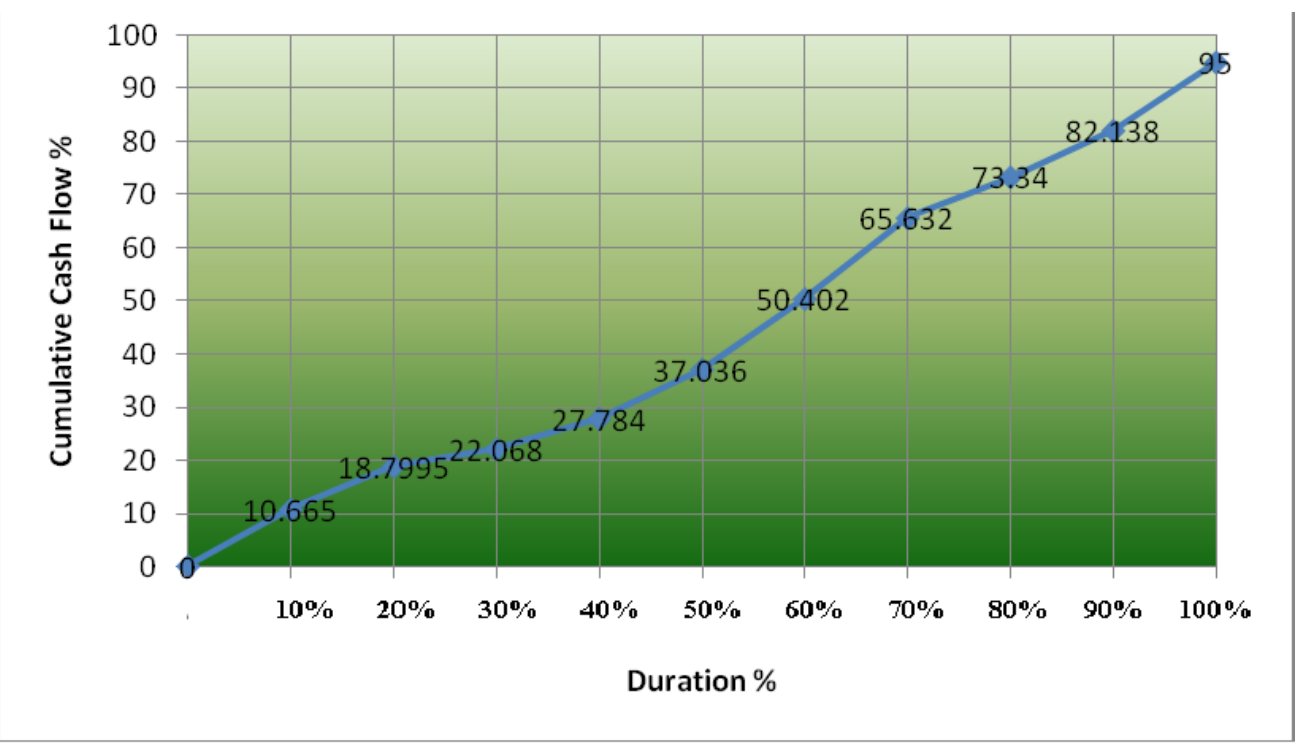

Figure5. Average Curve Estimated from Low budget strengthening curves.

\section{ESTIMATED EQUATIONS}

Using software specialized in polynomial equations; finally, an equation was got for each individual case of the previous six categories that express its case. Equations were proposed from Microsoft Excel so that it could be used to estimate the cash flow for newly projects. Six equations were got data from previous detailed projects.

\section{OVERLAY PROJECTS}

High overlay Projects:

$\mathrm{Y}=-0.0278+1.3303 \mathrm{X}-0.1939 \mathrm{X} 2+0.0122 \mathrm{X} 3-0.0003 \mathrm{X} 4 \ldots$ (1)

Mid overlay Projects:

$\mathrm{Y}=+0.0075+2.2957 \mathrm{X}-0.0532 \mathrm{X} 2-0.0009 \mathrm{X} 3+0.0001 \mathrm{X} 4 \ldots$ (2) 
Low overlay Projects:

$\mathrm{Y}=-0.0030+0.9677 \mathrm{X}-0.0892 \mathrm{X} 2+0.0069 \mathrm{X} 3-0.0002 \mathrm{X} 4 \ldots$

\section{STRENGTHENING PROJECTS}

High strengthening Projects:

$\mathrm{Y}=+0.0402-0.7100 \mathrm{X}+0.2037 \mathrm{X} 2-0.0099 \mathrm{X} 3+0.0002 \mathrm{X} 4 \ldots$

Mid strengthening Projects:

$\mathrm{Y}=-0.0626+1.1457 \mathrm{X}-0.0057 \mathrm{X} 2+0.0005 \mathrm{X} 3+0.0000 \mathrm{X} 4 \ldots$ (5)

Low strengthening Projects:

$\mathrm{Y}=+0.0023+0.3934 \mathrm{X}+0.1551 \mathrm{X} 2-0.0111 \mathrm{X} 3+0.0003 \mathrm{X} 4 \ldots$ (6)

By calculating errors between the actual cumulative cash flow percentage and the estimated cash flow percentage that got from the developed equations from each of six cases is going to compare the model results and its accuracy. The average of error percentage is calculated to be around less than $10 \%$. So predicted results could be got when using the proposed model to predict the cash flows for newly projects.

\section{CASH FLOW EXPECTATION MODEL FOR ROAD CONSTRUCTION}

The predictions of formulas gained from analysis that are used for creating create a user easy tool that might to calculate expected monthly invoices of payment for more projects simultaneously. Microsoft EXCEL is used for creating easy tool with its compatibility, flexibility, popularity, and ease for applying. The formulas are designed into same sheet to simplify designing possess. Proposed system was fully recognized in the following sections. The proposed model is working using custom function utilization that is performed into Microsoft Excel, the computerized estimation is developed with a custom functions processes by regression formulas from outputs projected payment amount and their analysis for every specific period which were visualized. The proposed model is implemented by 
Microsoft Excel sheet with applying simple functions and is named as Multi Road Projects Cash Flow Model "MRPCFM". The cash flow generator uses the basic information about the studied project and bid information to calculate and estimate the project payments and its timing. All estimates are calculated by the model. The model is capable for calculating owner needs, but for practicality and simplicity purpose, model is implemented to count with full detailed calculation up to 10 different construction road projects. This model contains seven sheets including statistics data that is unchangeable. The first sheet contains the project type and divides the project type into two sections (overlay and strengthening projects). Each type divided into three sections due to the budget range. The next six sheets contain equations which are developed for each type with its coefficients. These equations are used to calculate the cumulative cash flow through connecting the project with its chosen type as shown in the Fig. 6. Every sheet contains the 7th degree equation that was got for each individual case of the previous six categories and is expressed its case with its corresponding coefficients.

\section{Input variables}

The input sheet is called as a green sheet in the model. Each project has a single sheet with a unique number. For each sheet, there is input, and output data as shown in Figs. 5 to 7. Estimating monthly cash flow for any project needs to have basic information about the studied project. For applying the MRPCFM, the bid information must be enough. Input data divided into two types as follows: (1) basic information and (2) cash flow information. Firstly, basic information is the project identification data and its bid data such as project name, start date, duration, bid budget and type of project, (See Fig.6)

Secondly cash flow information that is shows the interval time between paying cash by days which can be determined for each project, in most construction project it use 30 days, and the advanced amount by EGP which could be paid at the start of the project to the contractors if any, (See Fig.7) 


\begin{tabular}{|c|c|c|c|}
\hline \multicolumn{4}{|c|}{ Basic input information } \\
\hline Project name & \multicolumn{3}{|c|}{ Strengthening and covering of Alex-Rasheed road $(10 \mathrm{~km}$} \\
\hline start date & 2-Oct-10 & & \\
\hline Duration & 1.00 & years & \\
\hline estimated finish date & 2-Oct-11 & & \\
\hline Estimated budget & 15000000 & L.E & \\
\hline Type of project & Strenthening & & \\
\hline Budget range & low & & \\
\hline Project Type & 6 & *----> & Low strenthing \\
\hline
\end{tabular}

Figure 6. Basic input information sheet.

Cash input informaion

interval time between paying cash

advanced cash

Figure 7. Cash input information sheet.

\section{Output variables}

The model is showed the output data in both forms cash flow table as shown in Fig 8 and cash flow diagram as shown in Fig 9. This helps for determining the amount of cash needed at any stage of project lifetime.

\begin{tabular}{|c|c|c|c|c|c|}
\hline \multicolumn{6}{|l|}{ Basic output } \\
\hline estimated period & & 365 & day & & \\
\hline \multicolumn{6}{|c|}{ Estimated cash flow through the whole project every month } \\
\hline Time of payment & passed time in days & Time charge $\%$ & $\begin{array}{c}\% \text { of cumulative } \\
\text { cashout } \%\end{array}$ & $\begin{array}{c}\text { cumulative cashout } \\
\text { (pound) }\end{array}$ & $\begin{array}{c}\text { Monthly cashout } \\
\text { (pound) }\end{array}$ \\
\hline 2-Oct-10 & 0 & 0.00 & 0.00 & 0.00 & 0.00 \\
\hline 1-Nov-10 & 30 & 8.22 & 8.85 & 1327509.68 & 1327509.68 \\
\hline 1-Dec-10 & 60 & 16.44 & 17.76 & 2664258.35 & 1336748.67 \\
\hline 31-Dec-10 & 90 & 24.66 & 22.17 & 3325450.62 & 661192.26 \\
\hline 30-Jan-11 & 120 & 32.88 & 25.13 & 3769725.38 & 444274.77 \\
\hline 1-Mar-11 & 150 & 41.10 & 30.43 & 4564919.36 & 795193.98 \\
\hline 31-Mar-11 & 180 & 49.32 & 39.46 & 5918671.80 & 1353752.44 \\
\hline 30-Apr-11 & 210 & 57.53 & 50.81 & 7621511.40 & 1702839.60 \\
\hline 30-May-11 & 240 & 65.75 & 61.66 & 9249713.71 & 1628202.31 \\
\hline 29-Jun-11 & 270 & 73.97 & 69.83 & 10475217.42 & 1225503.71 \\
\hline 29-Jul-11 & 300 & 82.19 & 75.53 & 11329887.93 & 854670.51 \\
\hline 28-Aug-11 & 330 & 90.41 & 81.81 & 12271416.54 & 941528.61 \\
\hline 27-Sep-11 & 360 & 98.63 & 92.65 & 13898143.66 & 1626727.13 \\
\hline 2-Oct-11 & 365 & 100.00 & 95.02 & 14253132.01 & 354988.34 \\
\hline
\end{tabular}

Figure 8. Cash flow data output. 


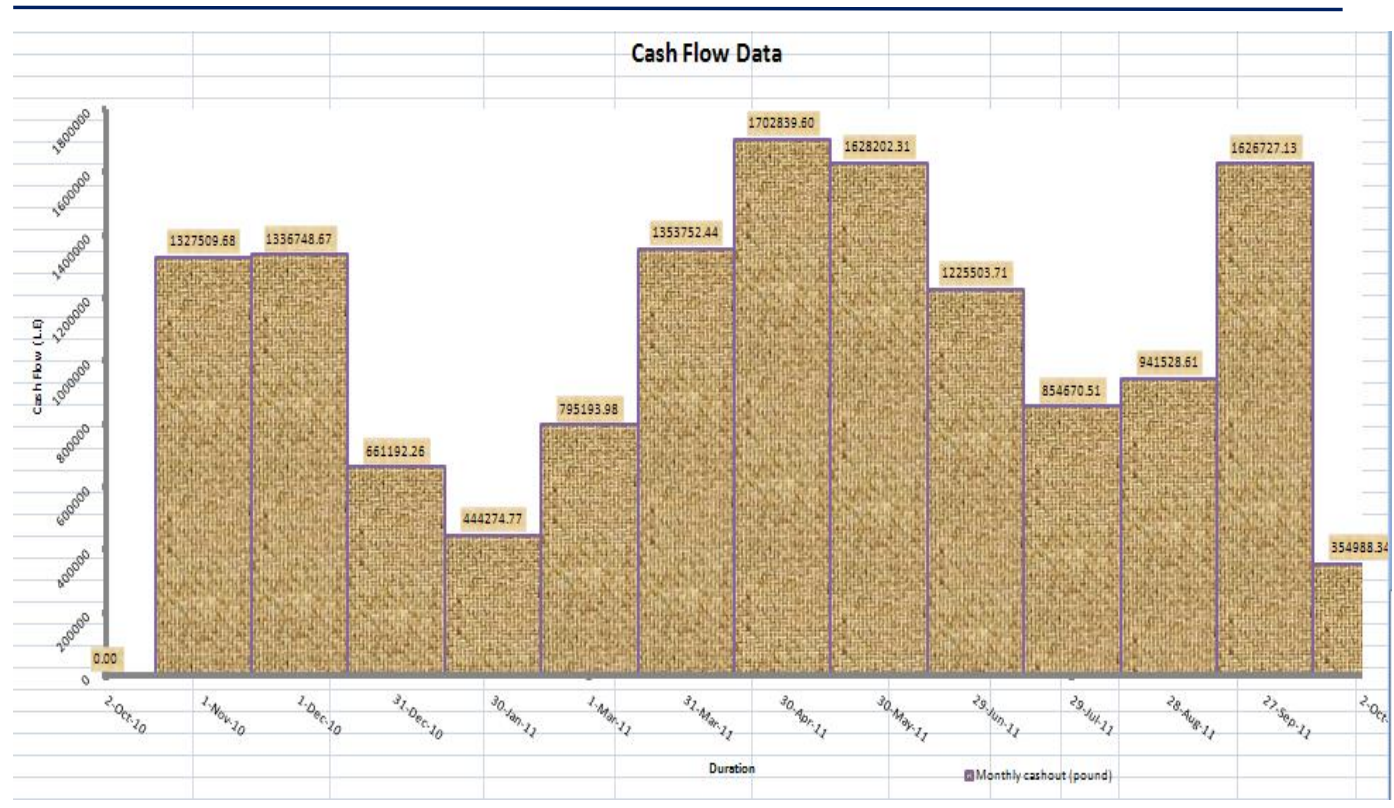

Figure9. Monthly Cash flow output diagram.

\section{CASE STUDY}

In this part of research, it is applied proposed model MRPCFM in a recent maintaining road project which is under construction and comparing the results with actual data that got from the monthly payment invoices to calculate percentage errors. The chosen project is considered as a stage of developing the Costal Road (Alex-Matrouh) from Foka to Matrouh with $60 \mathrm{~km}$ length. Developing the Costal Road of Alex/Matrouh project has a great importance and is a vital highway road. This road has a huge volume of traffic especially in summer and a lot of flows. The project of maintaining of Alex/Matrouh road from Foka to Matrouh which was started at first of August 2013 and the total duration of the project was expected to be 2 years. The project includes strengthening with base layers by $30 \mathrm{~cm}$ thickness and covering with two asphalt layers by $5 \mathrm{~cm}$ thickness for each. Also maintaining the current pavement in the distances with cracks and depression is included. The total budget of the project is estimated as 109,033,200.00 EGP. The contractor of the project is General Nile Company for Road construction which is considered as one of the main companies at road construction field. The company has got nine payments since the start of the project till now, 30 March 2014. The data of these payments will be showed in table 3 . 


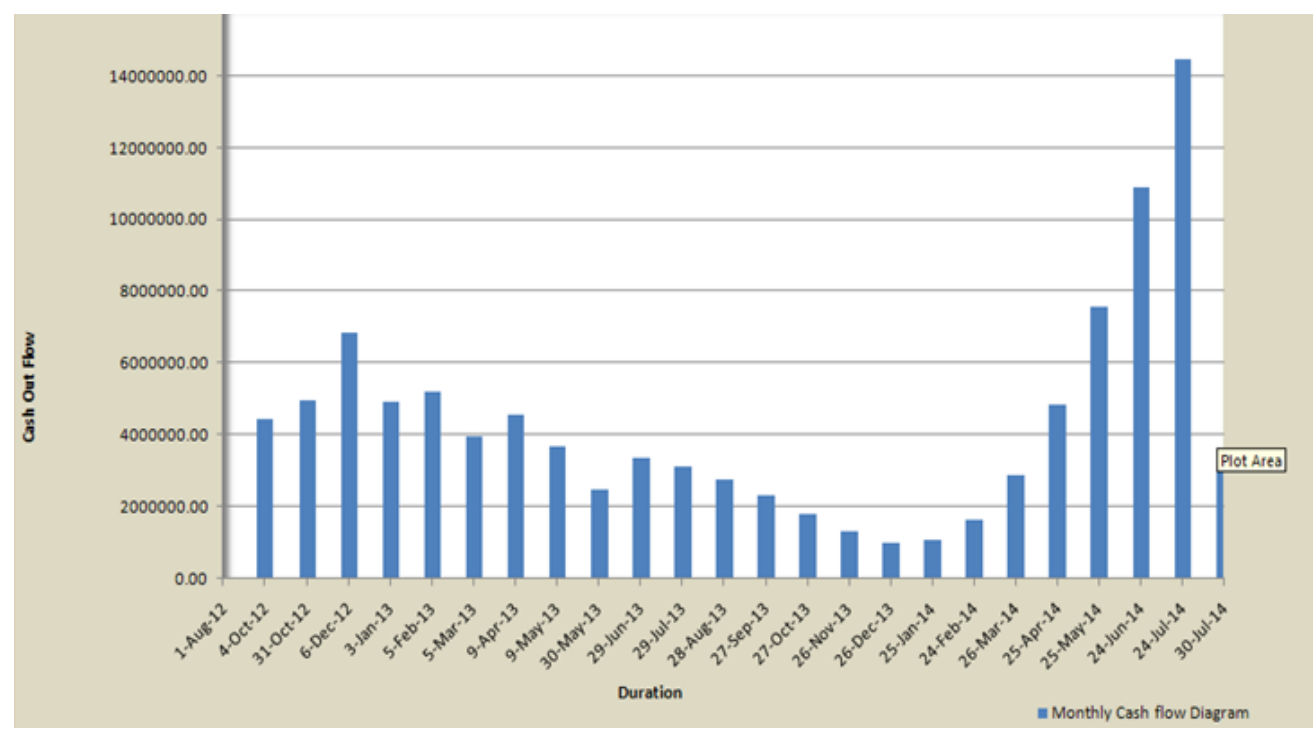

Figure 10. Monthly Cash flow output diagram of case study.

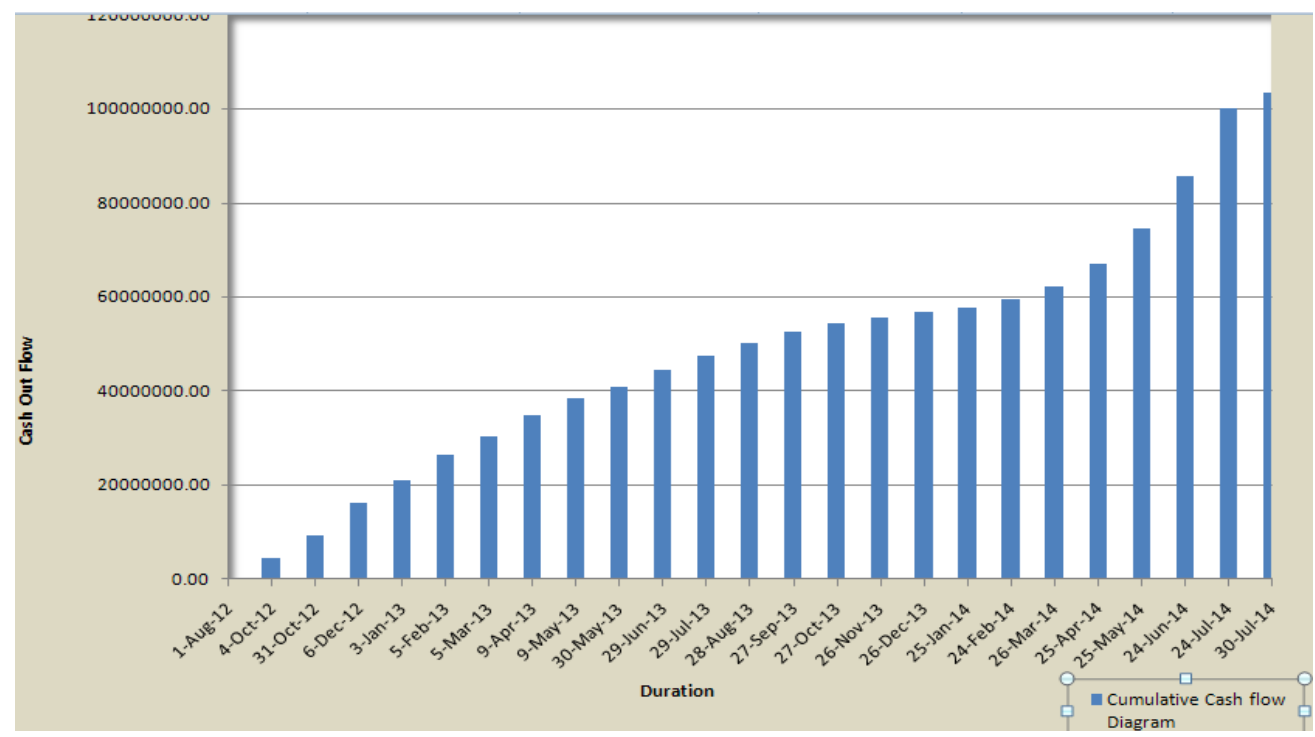

Figure 11. Cumulative Cash flow output diagram of case study

The project which is chosen as a case study is not completed yet as it started at August 2013 and supposed to be finished after two years, so the actual data of payments are collected in table 3 .

By comparing the results that got from the MRPCFM (See Fig. 10 and 11 ), with the actual data that got from the monthly payment invoices. 
The percentage of errors between the total actual and proposed cumulative cash flow are showed in table 3.

Table 3. Comparison between actual and estimated data for studied project.

\begin{tabular}{|c|c|c|c|}
\hline \multicolumn{2}{|c|}{ Project Name } & \multicolumn{2}{c|}{$\begin{array}{c}\text { Maintaining of Alex/Matrouh road from Foka to } \\
\text { Matrouh }\end{array}$} \\
\hline $\begin{array}{c}\text { Project time of } \\
\text { payments, \% }\end{array}$ & $\begin{array}{c}\text { Actual cumulative } \\
\text { cash flow \% }\end{array}$ & $\begin{array}{c}\text { Estimated cumulative } \\
\text { cash flow \% }\end{array}$ & $\begin{array}{c}\text { Error, } \\
\%\end{array}$ \\
\hline 0 & 0 & 0.00 & 0 \\
\hline 8.79 & 4.42 & 4.08 & 7.59 \\
\hline 12.50 & 7.69 & 8.64 & 12.42 \\
\hline 17.45 & 12.37 & 14.93 & 20.70 \\
\hline 21.29 & 19.61 & 19.47 & 0.70 \\
\hline 25.82 & 26.02 & 24.26 & 6.78 \\
\hline 29.67 & 29.31 & 27.91 & 4.78 \\
\hline 34.48 & 33.32 & 32.09 & 3.69 \\
\hline 38.60 & 36.94 & 35.46 & 4.01 \\
\hline 41.48 & 39.56 & 37.73 & 4.63 \\
\hline Average error percentage through the project duration & 7.26 \\
\hline
\end{tabular}

As shown in table 3 the average error percentage through the project duration didn't exceed 10\% which is approving the results of proposed model. The database of the MRPCFM depends on cash flow results of projects which are owned to General Authority of Roads, Bridges and Land transporting with different conditions and the surrounding circumstances. These conditions could be changed from an Authority to another and from country to another.

\section{CONCLUSIONS}

Road investment projects funding in Egypt is insufficient and need to increase in future. A proposed model which is named Multi Road Projects Cash Flow Model "MRPCFM" can be used to get a predicted view for cash flows of several road projects. This model can evaluate cash policies impact and operation of road construction projects on the financial state of an authority. Various types of projects with different budgets and their cash flows data are integrated with the model. So, this model should be applied in construction road projects to find an effective management strategy of cash flow. One essential feature in 
the proposed model can predict future cash flows for several road projects. The model input interfaces consist of basic information such as project name, start date, duration, total budget, and type of project. The owner will be capable for predicting cash flow for any road construction project under different tendering conditions. The model output interfaces consist of cash flow data table and diagrams that are shown the cash flow in full details with also cumulative cash flow during project duration. Only overlay and strengthening types of road projects were involved in proposed model. Every type was subdivided into three subcategories as (High budget, mid budget, and Low budget) for analysis. The classification was done according to completed construction road projects significant number after filtration. The curves of all cases were plotted for every category of classified projects. The average curve was plotted on the chart. The related cash flow formulation in different road project types and detailed corresponding plots were showed into research. For every individual case of previous six categories an equation was got to express its related case. These equations were used to estimate the cash flow for newly road projects. Finally at end of the paper, the verification and validation of the proposed software "MRPCFM" are tested using a real case study to demonstrate and verify the applications of prediction expressway of road construction project.

\section{References}

[1]. Michael Schellenger and Joann Noe Cross (1994) "FASB 95, Cash flow and Bankruptcy", Journal of Economics and Finance 18 (3), 261-274.

[2]. Cristine do Nascimento Mutti and Will Hughes (2002) "Cash flow management in construction firms", Greenwood, D (Ed.), 18th Annual ARCOM Conference, 2-4 September 2002, University of Northumbria. Association of Researchers in Construction Management, Vol. 1, 23-32.

[3]. Gholamreza Kordestani, Vahid Biglari, and Mehrdad Bakhtiari (2011) "Ability of combinations of cash flow components to predict financial distress", Malaya University, 50603 Kuala Lumpur, Malaysia.

[4]. Ibrahim Lubwama (2006) "Construction project Cash Flow Prediction for Owners", King Fahad University of Petroleum \& Minerals.

[5]. Navon R. (1996) "Company-level cash-flow management", Journal of Construction Engineering and Management, ASCE, 122 (1), 22-29.

[6]. Reinschmidt K.F. and Frank W.E. (1977) "Construction cash flow management system", Journal of Construction Engineering and Management, ASCE, 102 (4), 615-627. 
[7]. Kenley R. (1999) "Cash farming in building and construction: a stochastic analysis", Construction Management and Economics, 17 (4), 393-401.

[8]. Cygas D., Laurinavicius, A., Vaitkus, A., Perveneckas, Z., and Motiejunas, A, (2008) "Research of Asphalt Pavement Structures on Lithuanian Roads", Baltic Journal of Road and Bridge Engineering, 3 (2), 77-83.

[9]. Skrodenis B., Venckauskaite J., and Burinskiene (2009) "Substantiation of Communication Infrastructure Selection in Newly Developed Territories", Baltic Journal of Road and Bridge Engineering, 4 (2), 87-94.

[10]. Simon E., Gibson G., Haas C., O'Connor J., Somali B., and Zhang Z., (2002)" Development of a tool for expediting highway construction while retaining quality," University of Texas at Austin. Center for Transportation Research, Texas. Department of Transportation, United States. Federal Highway Administration.

[11].Joseph Prather (2008) "Cash Management Spending Plan", Transportation Cabinet, Frankfurt, Kentucky.

[12]. Tian Chen; Hao Hu; and Fengfeng Zhu (2020) "Developing a Hierarchical Road Layout Method for Large-Scale Construction Site" Journal of Construction Engineering and Management Volume 146 Issue 9.

[13]. Peter E. D. Love, D.Sc.; Chun-Pong Sing, Brad Carey; and Jeong Tai Kim (2015) "Estimating Construction Contingency: Accommodating the Potential for Cost Overruns in Road Construction Projects" Journal of Infrastructure Systems Volume 21 Issue 2.

[14]. Dan Chong; Lin Chen; and Jianxun Xie (2019) "Occupational Health Management in Road Construction Enterprises: A View of Cognitive Bias"International Conference on Construction and Real Estate Management.

[15]. Pramen P. Shrestha, Kabindra K. Shrestha, and Thomas K. Kandie (2017) "Effects of Change Orders on the Cost and Schedule of Rural Road Maintenance Projects" Journal of Legal Affairs and Dispute Resolution in Engineering and Construction Volume 9 Issue 3.

[16]. Yunping Liang, Baabak Ashuri, and Mingshu Li (2021) "Forecasting the Construction Expenditure Cash Flow for Transportation Design-Build Projects with a Case-Based Reasoning Model" Journal of Construction Engineering and Management, 147 (6): 04021043. 


\section{محاكاة نموذج التدفق النقدي لمشروعات البناء الضخمة في مصر في لوفر}

الملخص

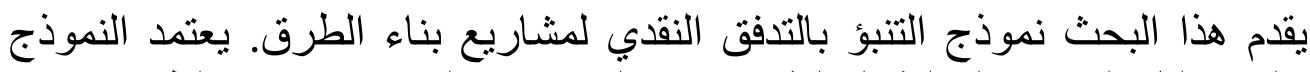

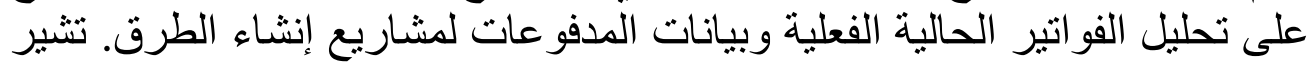

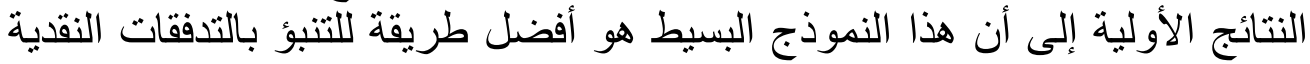

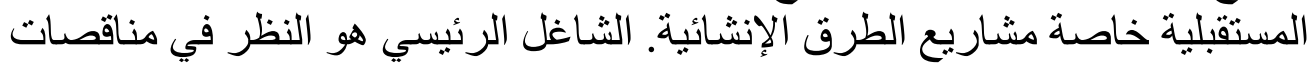

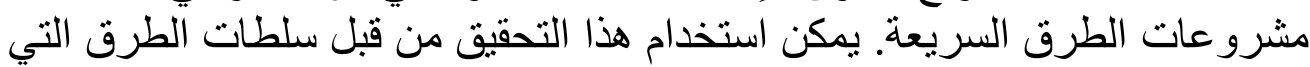

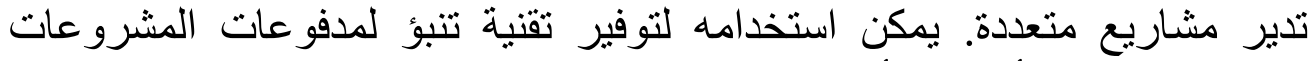

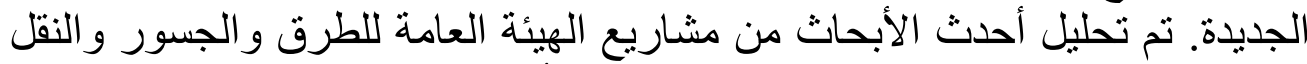

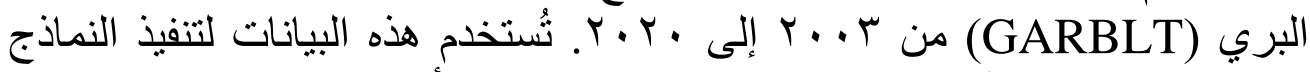

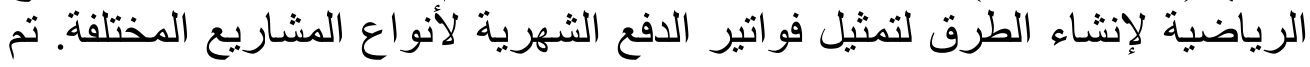

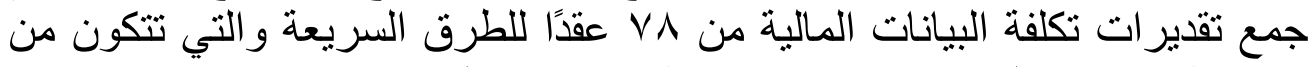

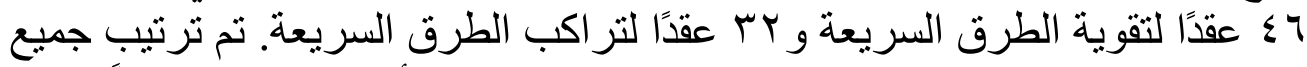

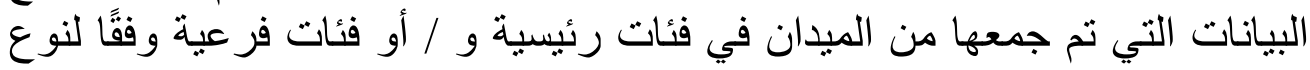

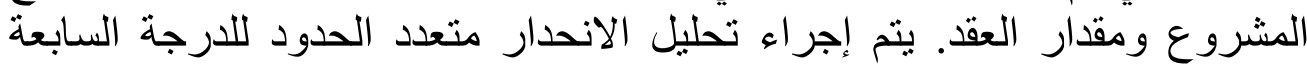

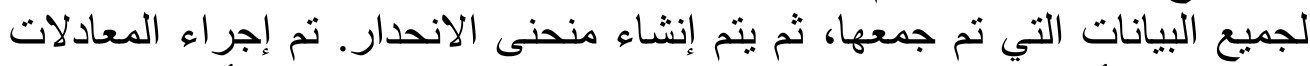

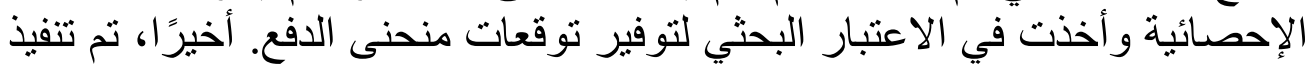

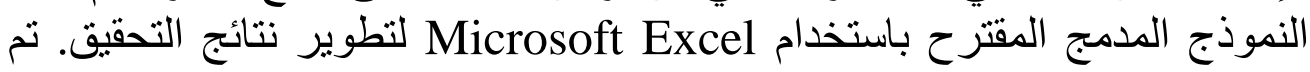

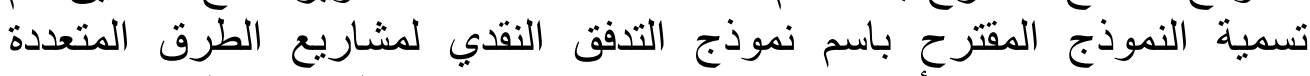
"MRPCFM"

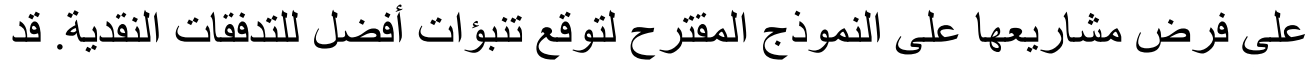

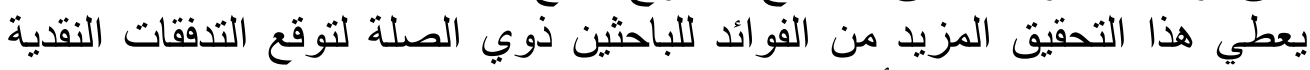

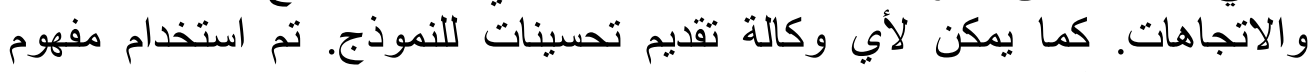

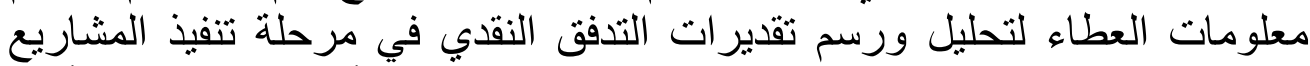

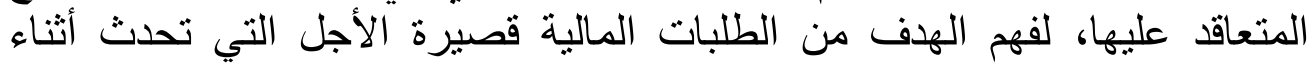

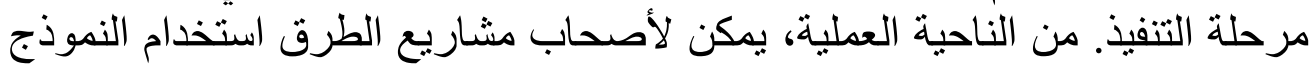

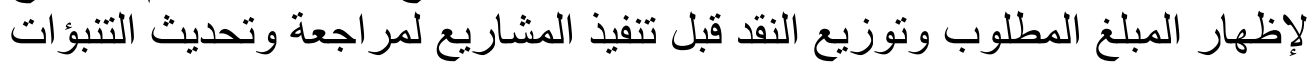
الجديدة من بيانات التدفقات النقدية الفعلية السابقة. 